\title{
THE SIGNAL RESPONSE LINEARITY IN PHTHALATES DETERMINATION USING ESI-MS METHOD WITH THE LOOP INJECTION TECHNIQUE
}

Tatjana D. Anđelković1* ${ }^{\star}$, Gordana M. Kocić , Darko H. Anđelković1, Ivana S. Kostić1, Danica S. Milojković ${ }^{1}$

${ }_{1}^{1}$ University of Niš, Faculty of Sciences and Mathematics, Niš, Serbia

2 University of Niš, Faculty of Medicine, Niš, Serbia

The possibility of using ESI-MS technique for the quantitative determination of six most commonly used phthalates (DMP, DnBP, BzBP, DEHP, DiNP, DiDP) was tested. The test was performed by using Loop technique for recording chromatogram obtained after the injection of different phthalates concentrations. The investigation was performed by determining the linear relationship between the concentration of phthalates and the peak areas in the chromatogram of mass range which corresponds to the molecular ion and ion adduct with sodium. The obtained results showed that there is linearity between the concentration of phthalates and peak areas in the chromatogram of monitoring molecular and adduct ions with sodium in case of DiNP $(r>0.999)$ and DMP ( $r>0.999$ for the molecular ion; $r>0.989$ for the ion adduct with sodium). The results obtained for the molecular ion in DiDP case showed a better linear relationship than the ion adduct with sodium, while the results obtained for BzBP showed opposite values. The same correlation coefficients for both monitoring ions, molecular ion and ion adduct with sodium were obtained for DEHP ( $r=0.98371$ and 0.98962, respectively). The correlation coefficients DnBP showed lower values than other linear coefficients ( $r=0.96034$ and 0.94669 , respectively). Although the signals of adduct ions with sodium are steady and intense, they are not reliable for quantification since the source of sodium ions is not defined and therefore, the actual amount of sodium in the sample may vary.
(ORIGINAL SCIENTIFIC PAPER) UDC 535.243

Keywords: phthalates, ESI-MS, Loop injection technique

\section{Introduction}

Phthalates are widely used industrial compounds. They are used as plasticizers and they are often added to various kinds of plastics to increase their softness, flexibility and stretching. These compounds are present in a wide variety of products such as toys, cosmetics, personal hygiene products, packaging for food and beverage, etc [1]. Phthalates are present in plastic compounds, but they are not chemically bound in plastic materials and later they can be leached into the surrounding medium [2]. The particular problem is the fact that if the medium surrounded by plastic material is food, cosmetics or some other products to which humans are directly exposed, phthalate migration may lead to the increased exposure, revealing their harmful effects. The migration of phthalates from packaging is conditioned by many factors, such as the type and the initial concentration of phthalates in the packaging, storage time, temperature, contact surface, fat content [3-5].

About one million tons of phthalates are produced in Europe per year. The most dominant phthalates are di-(2-ethylhexyl) phthalate (DEHP), diisodecyl phthalate (DiDP) and diisononyl phthalate (DiNP) $[6,7]$. The most common phthalates which occur in food and beverages contain 1 to 13 carbons in the carbon chain. The most important ones are DiNP, DiDP, DEHP, benzylbuthyl phthalate (BzBP), di-n-butyl phthalate (DnBP), dimethyl phthalate (DMP). They are the subject to European Union Regulation No. 793/93, because they are used as additives in plastic materials that come into contact with food according to EU Directive 2007/19/EC. It was found that those phthalates when used as plasticizers may cause hormonal balance disruption and disruption of endocrine glands. They can reduce male fertility, cause genital deformities, the increased number of cases of testicular cancer and a decreased production of testosterone in the young boy's body [8].

The most commonly used method for phthalate determination is gas chromatography (GC) coupled with various detection methods, as electron capture (ECD) [9], flame ionization (FID) [10], mass spectrometry (MS) [11] etc. HPLC method can be used in combination with different detection methods such as UV and MS $[12,13]$.

Electrospray ionization-mass spectrometry (ESI-MS) is used for the detection and characterization of one

\footnotetext{
* Author address: Tatjana D. Anđelković, University of Niš, Faculty of Sciences and Mathematics Višegradska 33, 18000 Niš, Serbia

E-mail: tatjanaan@gmail.com

The manuscript received: January, 28, 2015.

Paper accepted: February, 25, 2015.
} 
or more ionic species in the solution, and can be very useful in the studies of multi-component systems [14]. The study of the solution in equilibrium comprising the simultaneous detection, identification and quantification of many species, the distribution of which depends on the $\mathrm{pH}$, concentration etc. could be performed by using the ESI-MS technique which is, although rarely used in this kind of study, capable of giving a quick and informative insight to the solution species. ESI-MS allows mass spectra to be obtained directly from a liquid sample. Soft conditions of ESI ionization sources (i.e. soft ionization mode) minimize fragmentation, and molecular and ionic species are mainly unchanged. Depending on the charge of ions in the solution, or potential to produce ions with positive or negative charge, positive or negative ion mode can be applied (ESI + or ESI-) in order to get the optimal results. Relative abundance (\%) of individual species can be obtained directly from the intensity of molecular peaks. The soft conditions which provide spectrum with a sufficient sensitivity and low detection limit, at the concentration values down to $10^{-6} \mathrm{M}$, represent one of the main advantages of ESI-MS method for the analysis. This allows the analysis of solutions at concentration levels, which are more close to those usually encountered in the environmental samples or biological samples and a relatively small amount (volume) of the sample required for the analysis also extends the capabilities of this method [15].

The subject of this paper is to assess the possibility of using ESI-MS technique for obtaining the linear responsivity, as the initial parameter for quantitative determination, by using the Loop injection technique. The occurrence of linear relationship between phthalates concentrations and peak areas in the Loop chromatogram of a particular mass range is investigated.

\section{Experimental}

Reagents and equipment

High purity phthalates (> 98.7\%) were used as standards. DMP, DnBP, BzBP, DEHP, DiNP and DiDP were purchased from Sigma-Aldrich. Methanol, HPLC purity, was purchased from Baker, dimethyl chloride, from Merck, ultra pure deionized water was obtained by the purification system PW Series Ultra Pure Water System (Heal Force Co., Hong Kong, PR China). The ESI-MS measurements were performed on Thermo Finnigan (USA) LCQ Deca with a quadrupole ion trap mass analyzer and the auxiliary equipment.

Preparation of standard working solution of phthalates

All standards and working solutions of phthalates were prepared in methanol. Standard solutions were prepared at the concentration of about $1 \mathrm{mg} / \mathrm{mL}$ by measuring the accurate mass of phthalate on the analytical balance (KERN 19013) with a precision of $\pm 0.00001 \mathrm{~g}$, and then by dissolving in methanol. By diluting standard solutions, the operating solutions were obtained in the concentration range $10-100 \mathrm{mg} / \mathrm{mL}$. Individual working solutions in the concentration of $1 \mu \mathrm{g} / \mathrm{mL}$ were used for identifying a retention time of phthalate. The solutions were kept at $4{ }^{\circ} \mathrm{C}$.

Laboratory glassware was used during the experimentation. Glassware was washed with hot water and soap, then rinsed with ultra-pure deionized water. After that, glassware was washed with dichloromethane and dried. Dry glassware was wrapped in aluminum foil and kept untill the time of use in order to avoid contamination of phthalates from the air.

Analysis of linearity of curve obtained by determining phthalate after the Loop injection technique

Determined concentrations of phthalate in methanol were analyzed after injection by Loop technique. The sample was introduced via HAMILTON syringe with volume of $250 \mu \mathrm{L}, \mathrm{d}=2.30 \mathrm{~mm}$, by means of a multiport rotary valve $20 \mu \mathrm{L}$ "Loop" volume, which is connected to the ESI via silica capillary system $d=100 \mu \mathrm{m}$. The solutions were analyzed by the flow-injection ESI-MS method using nitrogen as an auxiliary gas, in the positive (+) mode. Methanol was introduced with the flow rate of $100 \mathrm{~mL} /$ $\mathrm{min}$, and the duration of the analysis (recording of $L o o p$ chromatogram) was 90 seconds on the average, allowing the whole chromatographic peak to be completely covered by the set time of the analysis.

Chromatographic peak is shown by time baseline on $\mathrm{x}$-axis and relative signal intensity (relative abundance) on y-axis. The areas of ESI-MS Loop chromatogram peaks were expressed by absolute units using LCQ Tune Plus ver. 1.3 program (count-second units), and the geometry of the peak was defined by using ICIS $®$ algorithm (Interactive Chemical Information System) within Finnigan XcaliburTM XSQ 1.3 software, which is used for recording and interpretation of mass spectra. When Loop chromatograms were obtained, first the consistency of TIC (Total Ion Current) peak was checked, then Loop chromatograms of the MRC mode (Mass Range chromatogram) were derived, and relative intensity of the signal was filtered to the required range $\mathrm{m} / \mathrm{z}$. The target range was set with the tolerance of $\mathrm{m} / \mathrm{z} \pm 1.0$ compared to the nominal mass of the selected monitoring ion (usually monoisotopic protonated molecular ion or ion adduct with sodium). By using the ICIS $₫$ module of XcaliburTM 1.3 software, the areas of each ESI-MS ion current chromatogram of $20 \mu \mathrm{L}$ Loop injection volume for the defined mass range of the analyte were calculated. The areas are presented in absolute non-dimensional (arbitrary) units of the XcaliburTM software (count-second units) (5 total solutions of different concentrations, in the range of about 0.25 - $45 \mathrm{mg} / \mathrm{mL}$ ).

The procedure was repeated for three times and the average value of the obtained Loop chromatogram areas, after the injection of the solution with certain phthalate concentration was calculated and adopted for further work. 


\section{Results and Discussion}

Protonated ions $[\mathrm{M}+\mathrm{H}]^{+}$, as typical monitoring-ions, were used for defining ESI-MS Loop chromatographic peaks, considering their good signal intensity and what is in accordance with conventional analytical practices [16]. Also, ion adducts with sodium $[\mathrm{M}+\mathrm{Na}]^{+}$were taken into consideration as monitoring ions. Table 1 shows characteristic ions for each investigated phthalate, and the relative intensity of each characteristic peak.

Quantification was performed by calculating the area of ESI-MS ion current chromatograms of Loop injections for the appropriate mass range $(\mathrm{m} / \mathrm{z}$ of molecular ion, \pm 1.0 ) obtained by analyzing the series of phthalate solutions. The recorded MS spectra of all investigated

a)

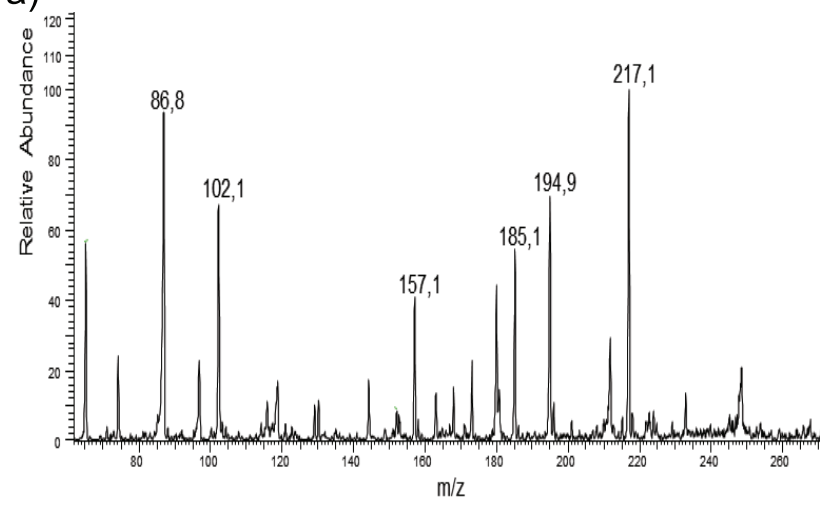

c)

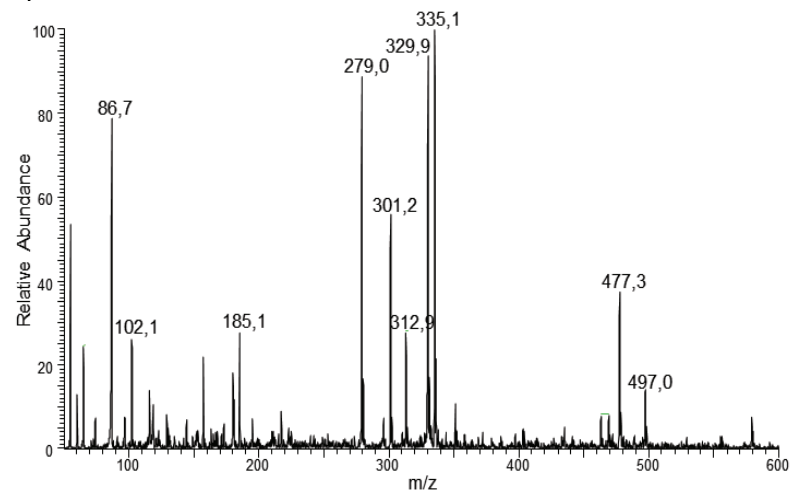

e)

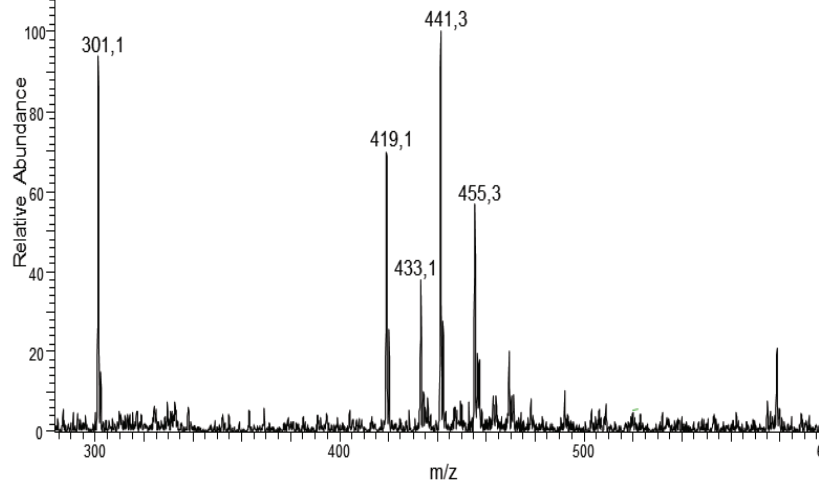

phthalates are shown in Fig. 1. Figure 1 shows the ESI-MS spectra of all investigated phthalates: DMP (c = $\left.31,50 \mu \mathrm{g} / \mathrm{mL} ; \mathrm{m} / \mathrm{z} 195[\mathrm{M}+\mathrm{H}]^{+}, \mathrm{m} / \mathrm{z} 217[\mathrm{M}+\mathrm{Na}]^{+}\right)$; DnBP $\left(\mathrm{c}=25,00 \mu \mathrm{g} / \mathrm{mL} ; \mathrm{m} / \mathrm{z} 279[\mathrm{M}+\mathrm{H}]^{+}, \mathrm{m} / \mathrm{z} 301[\mathrm{M}+\mathrm{Na}]^{+}\right.$); $\operatorname{BzBP}\left(\mathrm{c}=45,00 \mu \mathrm{g} / \mathrm{mL} ; \mathrm{m} / \mathrm{z} 313[\mathrm{M}+\mathrm{H}]^{+}, \mathrm{m} / \mathrm{z} 335\right.$ $\left.[\mathrm{M}+\mathrm{Na}]^{+}\right) ; \operatorname{DEHP}\left(\mathrm{c}=29,10 \mu \mathrm{g} / \mathrm{mL} ; \mathrm{m} / \mathrm{z} 391[\mathrm{M}+\mathrm{H}]^{+}, \mathrm{m} / \mathrm{z}\right.$ $\left.413[\mathrm{M}+\mathrm{Na}]^{+}\right) ; \operatorname{DiNP}\left(\mathrm{c}=25,10 \mu \mathrm{g} / \mathrm{mL} ; \mathrm{m} / \mathrm{z} 419[\mathrm{M}+\mathrm{H}]^{+}\right.$, $\mathrm{m} / \mathrm{z} 441[\mathrm{M}+\mathrm{Na}]^{+}$) and DiDP $(\mathrm{c}=34,60 \mu \mathrm{g} / \mathrm{mL} ; \mathrm{m} / \mathrm{z} 447$ $\left.[\mathrm{M}+\mathrm{H}]^{+}, \mathrm{m} / \mathrm{z} 469[\mathrm{M}+\mathrm{Na}]^{+}\right)$with $\mathrm{CH}_{3} \mathrm{OH}$ as a solvent in the positive ionization mode. All phthalates showed $[\mathrm{M}+\mathrm{Na}]^{+}$ as the base peak, except DnBP. The spectrum of DnBP showed $[\mathrm{M}+\mathrm{H}]^{+}$as the most abundant ion.

b)

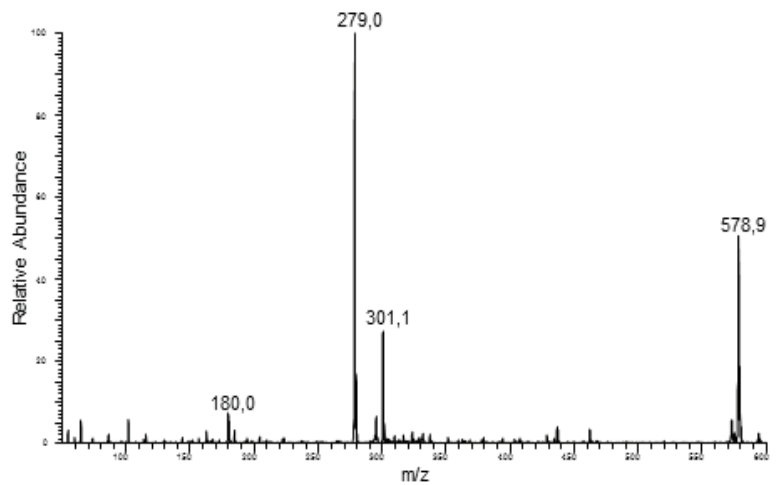

d)

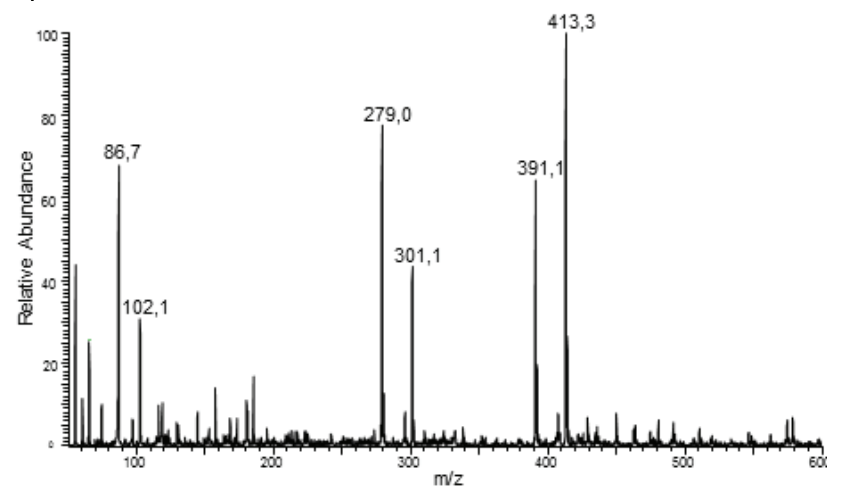

f)

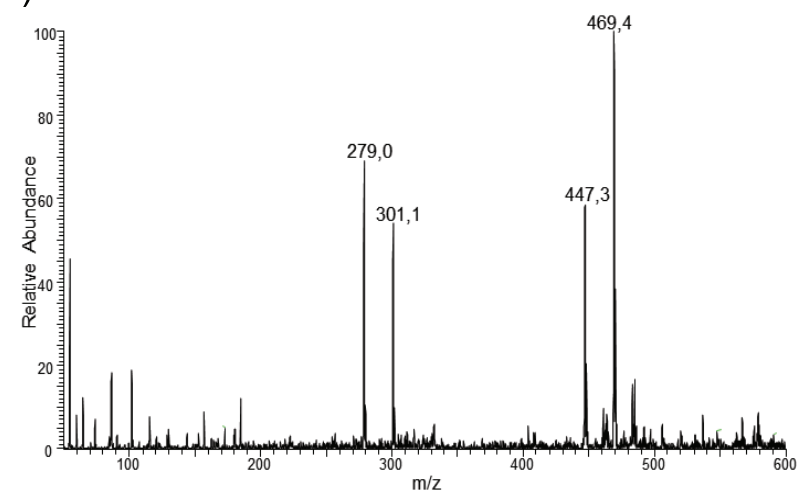

Figure 1. ESI-MS spectra (a) DMP; (b) DnBP; (c) BzBP; (d) DEHP; (e) DiNP; (f) DiDP. 
The peak area of the selected mass range in ion current chromatogram for BzBP is shown in Fig. 2. Quantification was enabled by injecting the accurate volume of 20 $\mu \mathrm{L}$ of phthalate solution by Loop system. All Loop chromatograms were properly shaped and showed satisfactory integrity peak for both TIC and the required range $\mathrm{m} / \mathrm{z}$.

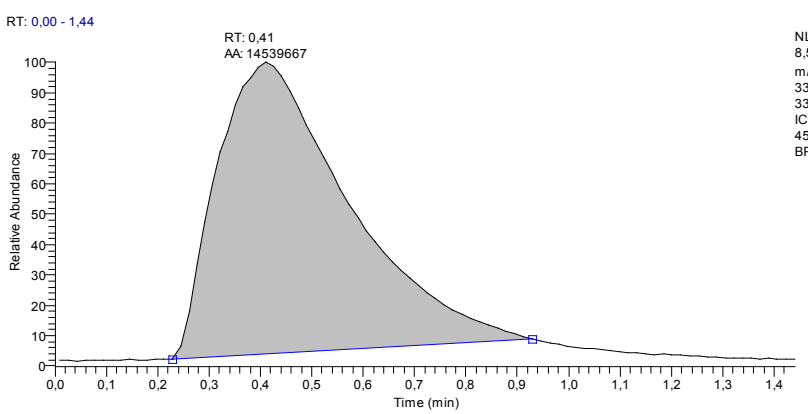

Figure 2. ESI-MS chromatogram obtained for BzBP, injected by Loop technique $\mathrm{c}=45 \mu \mathrm{g} / \mathrm{mL}$, solvent $\mathrm{CH}_{3} \mathrm{OH}$, positive ionization mode, flow rate $=100 \mu \mathrm{L} / \mathrm{min}$.

The values of ion current chromatogram peak areas are plotted vs. phthalate concentrations and this two-variable correlation is described by linear fitting (Fig. 3). The quantification possibility was based on the fact that all areas of TIC chromatograms are in direct linear function with the intensities of peaks in the mass spectrum (obtained by observing the ion signals within the appropriate $\mathrm{m} / \mathrm{z}$ range) for the investigated range of concentrations [17].

Table 1. Characteristic monitoring ions of the investigated phthalates used for the determination by ESI-MS Loop injection technique

\begin{tabular}{lccc}
\hline Phthalate & $\begin{array}{c}\text { Peak } \\
(\mathrm{m} / \mathrm{z})\end{array}$ & Monitoring ion & $\begin{array}{c}\text { Relative abundance } \\
(\%)\end{array}$ \\
\hline DMP & 195 & {$[\mathrm{M}+\mathrm{H}]^{+}$} & 70 \\
& 217 & {$[\mathrm{M}+\mathrm{Na}]^{+}$} & 100 \\
DnBP & 279 & {$[\mathrm{M}+\mathrm{H}]^{+}$} & 100 \\
& 301 & {$[\mathrm{M}+\mathrm{Na}]^{+}$} & 30 \\
BzBP & 313 & {$[\mathrm{M}+\mathrm{H}]^{+}$} & 30 \\
& 335 & {$[\mathrm{M}+\mathrm{Na}]^{+}$} & 100 \\
DEHP & 391 & {$[\mathrm{M}+\mathrm{H}]^{+}$} & 70 \\
& 413 & {$[\mathrm{M}+\mathrm{Na}]^{+}$} & 100 \\
DiNP & 419 & {$[\mathrm{M}+\mathrm{H}]^{+}$} & 70 \\
& 441 & {$[\mathrm{M}+\mathrm{Na}]^{+}$} & 100 \\
DiOP & 447 & {$[\mathrm{M}+\mathrm{H}]^{+}$} & 70 \\
& 469 & {$[\mathrm{M}+\mathrm{Na}]^{+}$} & 100 \\
\hline
\end{tabular}

Calculating the area of Loop chromatogram peaks for the mass range, $\mathrm{m} / \mathrm{z}$ was obtained using the algorithm ICIS (EXCALIBURE $®$ program), and derived values are shown in Table 2.
Table 2. Peak areas of ESI-MS chromatograms in the TIC mode after the sample injection by Loop technique, for a corresponding range of $\mathrm{m} / \mathrm{z}$ values of $[\mathrm{M}+\mathrm{H}]^{+}$and $[\mathrm{M}+\mathrm{Na}]^{+}$ions, depending on the phthalate concentration.

\begin{tabular}{|c|c|c|}
\hline $\begin{array}{l}\text { Concentration of } \\
\text { phthalate, } \mu \mathrm{g} / \mathrm{mL}\end{array}$ & $\begin{array}{l}\text { Peak area }[\mathrm{M}+\mathrm{H}]^{+} \text {ion } \\
\text { (abs. units), } \times 10^{6}\end{array}$ & $\begin{array}{l}\text { Peak area }[\mathrm{M}+\mathrm{Na}]^{+} \text {ion } \\
\quad(\text { abs. units }), \times 10^{6}\end{array}$ \\
\hline DMP & $\mathrm{m} / \mathrm{z}$ 194-196 & $\mathrm{m} / \mathrm{z} 216-218$ \\
\hline 0.031 & 0.1 & 0.1 \\
\hline 0.315 & 0.6 & 1.0 \\
\hline 3.150 & 2.1 & 2.1 \\
\hline 15.75 & 4.1 & 8.7 \\
\hline 31.50 & 8.2 & 17.3 \\
\hline DnBP & $m / z$ 277-279 & $\mathrm{m} / \mathrm{z}$ 300-302 \\
\hline 0.025 & 0.1 & 0.1 \\
\hline 0.251 & 0.2 & 3.7 \\
\hline 2.510 & 13.1 & 5.9 \\
\hline 12.55 & 18.2 & 7.5 \\
\hline 25.10 & 35.3 & 15.3 \\
\hline BzBP & $\mathrm{m} / \mathrm{z} 312-314$ & $m / z$ 334-336 \\
\hline 0.045 & 0.05 & 0.0 \\
\hline 0.450 & 0.3 & 0.3 \\
\hline 4.500 & 1.9 & 2.6 \\
\hline 22.50 & 2.7 & 8.4 \\
\hline 45.00 & 5.1 & 17.1 \\
\hline DEHP & $m / z$ 390-392 & $\mathrm{m} / \mathrm{z} 412-414$ \\
\hline 0.029 & 0.05 & 0.09 \\
\hline 0.291 & 0.3 & 0.5 \\
\hline 2.915 & 4.0 & 5.2 \\
\hline 14.57 & 7.8 & 10.5 \\
\hline 29.15 & 14.1 & 21.6 \\
\hline DiNP & $\mathrm{m} / \mathrm{z} 418-420$ & $\mathrm{~m} / \mathrm{z} 440-442$ \\
\hline 0.025 & 0.2 & 0.0 \\
\hline 0.251 & 1.2 & 1.3 \\
\hline 2.510 & 8.6 & 8.6 \\
\hline 12.55 & 31.5 & 36.0 \\
\hline 25.10 & 63.0 & 72.0 \\
\hline DiDP & $\mathrm{m} / \mathrm{z} 446-448$ & $\mathrm{~m} / \mathrm{z} 468-470$ \\
\hline 0.035 & 0.1 & 0.1 \\
\hline 0.346 & 0.5 & 0.7 \\
\hline 3.465 & 2.7 & 4.8 \\
\hline 17.32 & 5.8 & 8.9 \\
\hline 34.65 & 11.5 & 17.9 \\
\hline
\end{tabular}

Figure 3 shows the ratio between the phthalate concentration and peak areas of ESI-MS Loop chromatograms for a typical mass range of the protonated molecular ions and adduct ions with sodium, recorded in the positive ionization mode.

Parameters of linear equations obtained by the linear regression analysis on data sets (shown in Figure 3), as well as respective correlation coefficients are summarized in Table 3.

The results presented in Table 3 show that the highest degree of the linear correlation between two variables is in the $\mathrm{m} / \mathrm{z}$ range which corresponds to $[\mathrm{M}+\mathrm{Na}]^{+}$ion, with exceptions for DnBP and DiDP. Although the signal of adduct ions with sodium was more intensive, this ion is not reliable for quantification because the source of sodium ions is not defined and therefore the present amount of sodium that occurs in the sample may vary. 
a)

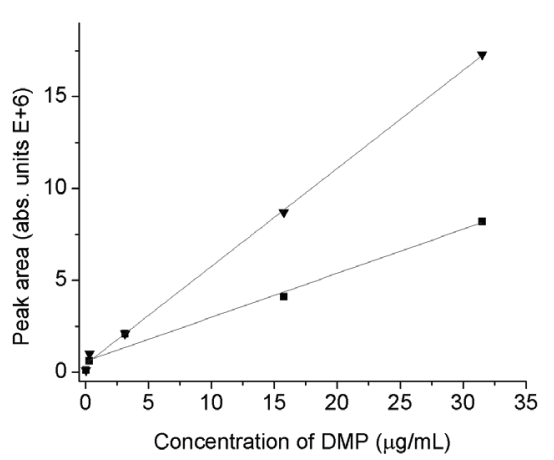

c)

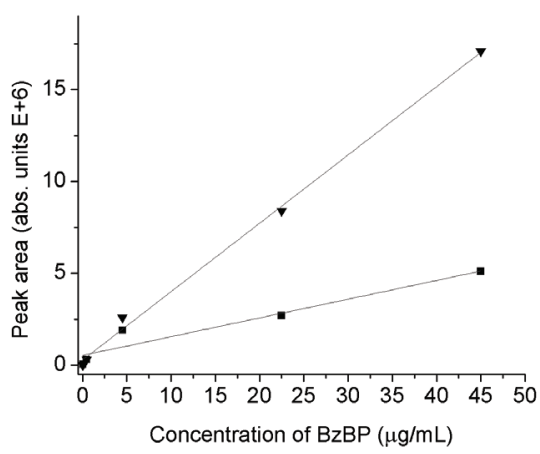

e)

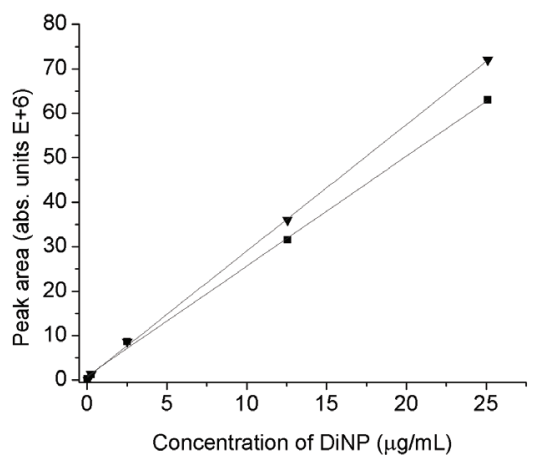

b)

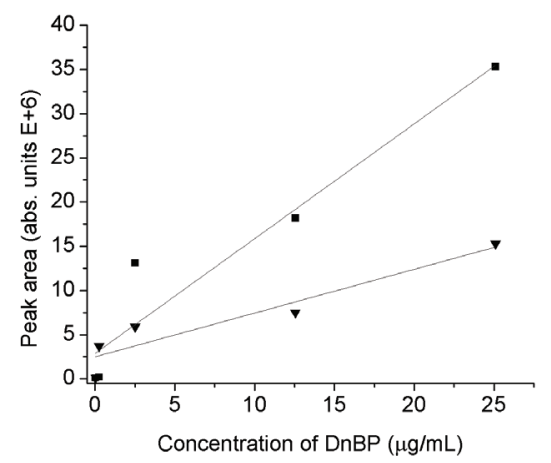

d)

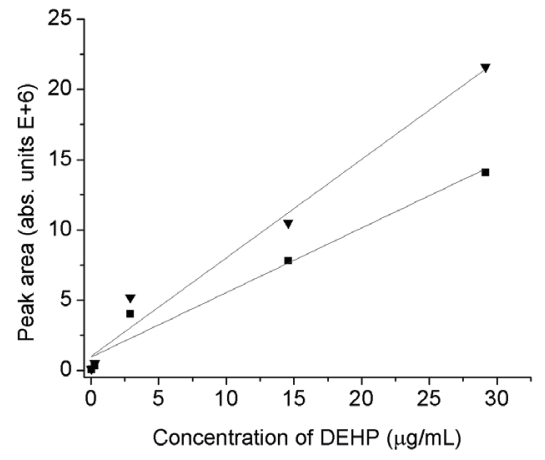

f)

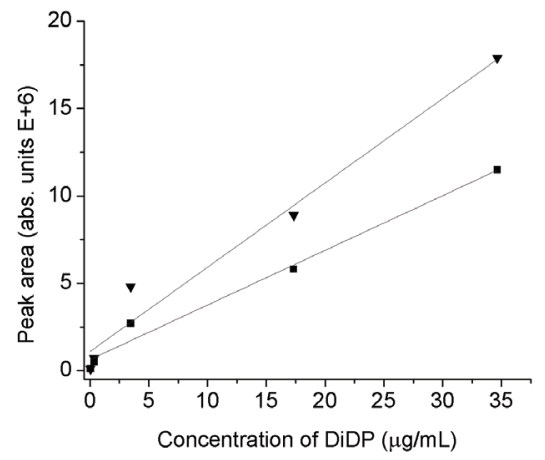

Figure 3. The ratio between the concentration of phthalate and the peak area of chromatogram after Loop injection: (a) DMP; (b) DnBP; (c) BzBP; (d) DEHP; (e) DiNP; (f) DiDP; - - protonated molecular ion; $\boldsymbol{\nabla}$ - ion adduct with sodium; solvent $\mathrm{CH}_{3} \mathrm{OH}$, positive ionization mode.

Table 3. Linear equations and correlation coefficients obtained by plotting peak areas vs. the phthalates concentration

\begin{tabular}{lcccc}
\hline Phthalate & Equation for $[\mathrm{M}+\mathrm{H}]^{+}$ & $r$ & Equation for $[\mathrm{M}+\mathrm{Na}]^{+}$ & $r$ \\
\hline DMP & $\mathrm{Y}=0.5848+0.2399 \mathrm{X}$ & 0.98959 & $\mathrm{Y}=0.4217+0.5339 \mathrm{X}$ & 0.99928 \\
DnBP & $\mathrm{Y}=2.8767+1.2988 \mathrm{X}$ & 0.96034 & $\mathrm{Y}=2.4974+0.4949 \mathrm{X}$ & 0.94669 \\
BzBP & $\mathrm{Y}=0.5295+0.1021 \mathrm{X}$ & 0.96496 & $\mathrm{Y}=0.2831+0.3722 \mathrm{X}$ & 0.99857 \\
DEHP & $\mathrm{Y}=0.9262+0.4604 \mathrm{X}$ & 0.98371 & $\mathrm{Y}=0.9840+0.7022 \mathrm{X}$ & 0.98962 \\
DiNP & $\mathrm{Y}=0.9202+2.4705 \mathrm{X}$ & 0.99946 & $\mathrm{Y}=0.5856+2.8433 \mathrm{X}$ & 0.99983 \\
DiDP & $\mathrm{Y}=0.6254+0.3130 \mathrm{X}$ & 0.99216 & $\mathrm{Y}=1.0898+0.4829 \mathrm{X}$ & 0.98634 \\
\hline
\end{tabular}


Comparing the correlation coefficients $(r)$ of the curves obtained for the investigated phthalates in the range of $\mathrm{m} / \mathrm{z}$ values which correspond to $[\mathrm{M}+\mathrm{H}]^{+}$, the highest coefficient for DiNP and DiDP was obtained. The equations which were obtained for DMP and DEHP showed lesser linearity, while the lowest correlation coefficients were obtained for BzBP and DnBP.

Comparing the experimental correlation coefficients for $\mathrm{m} / \mathrm{z}$ values of $[\mathrm{M}+\mathrm{Na}]^{+}$monitoring ions, the following sequence was shown: DiNP > DMP > BzBP > DEHP > DiDP $>$ DnBP, while $[\mathrm{M}+\mathrm{H}]^{+}$monitoring ions showed the sequence: DiNP > DiDP > DMP > DEHP > BzBP > DnBP. In both cases DiNP showed the highest value of the correlation coefficient, while DnBP gave the lowest values. In case of DMP, the ion adduct with sodium gave a more intense peak. DiDP showed that the protonated molecular ion was more reliable for monitoring, whereas in the case of BzBP it was the ion adduct with sodium. The study of DEHP showed approximately the same correlation coefficients for both monitoring ions, and in the case of DnBP, linearity coefficients showed the lowest values.

\section{Conclusion}

The possibility of using ESI-MS method for the quantitative determination of phthalates using the Loop injection technique was investigated. The possibility of ESI-MS application was determined by comparing the indicator of linearity, correlation coefficient $(r)$ between the concentration and the peak area of the phthalate ions in Loop chromatogram for a specific mass range. The existence of linearity was tested for the mass ranges that correspond to the protonated molecular ion and to the ion adduct with sodium. It can be concluded that ESIMS Loop injection technique is suitable for the quantitative determination of some of the most common alkyl phthalates. The study showed that the method can be applied for the determination of DiNP and DMP by using both monitoring ions. The investigation of DiDP showed that the protonated molecular ion is a more reliable ion for monitoring, whereas in the case of BzBP adduct $[\mathrm{M}+\mathrm{Na}]^{+}$may be preferable, assumed that the sufficient concentration of $\mathrm{Na}^{+}$is provided. The study of DEHP showed approximately the same correlation coefficients for both monitoring ions. The correlation coefficients obtained after analyzing DnBP showed the lowest values in the group of the investigated compounds. Although the signals of adduct ions with sodium were more intensive, this ion species could not be reliable for quantification because the concentration of sodium ions is not standardized and therefore the present amount of $\mathrm{Na}^{+}$occurring in the sample may vary.

\section{Acknowledgements}

This study was supported by the Ministry of Education, Science and Technological Development of the Republic of Serbia and was performed as a part of Project TR 31060.

\section{References}

[1] H.M. Koch, L.M: Gonzales-Reche, J. Angerer, On-line clean-up by multidimensional liquid chromatographyelectrospray ionization tandem mass spectrometry for high throughput quantification of primary and secondary phthalate metabolites in human urine, Journal of Chromatography B 784 (2003) 169-182

[2] C. Perez Feas, M.C. Baricela-Alonso, P. Bermejo-Barrera, Direct LC-ES-MS/MS determination of phthalates in physiological saline solutions, Journal of Chromatography B 879 (2011) 231-235

[3] J. D.Carrillo, C.Salazar, C. Moreta, M. T. Tena, Determination of phthalates in wine by headspace solidphase microextraction followed by gas chromatographymass spectrometry: Fibre comparison and selection, Journal of Chromatography A, 1164(1-2) (2008) 248-261.

[4] K. Holadová, J. Hajšlová, A comparison of different ways of sample preparation for the determination of phthalic acid esters in water and plant matrices, International Journal of Environmental Analytical Chemistry, 59(1) (1995) 43-57.

[5] C. Simoneau, P. Hannaer, Stability testing of selected plastics additives for food contact in EU aqueous, fatty and alternative simulants, Food Additives and Contaminants, 16(5) (1999) 197-206.

[6] D. Zhang, H. Lui, Y. Liang, C. Wang, H. Liang, H. Cai, Distribution of phthalate esters in the groundwater of Jianghan plain, Hubei, China, Earth Sci. China 3 (2009) 73-79

[7] H. M. Koch, B. Rossbach, H. Drexler, J. Angerer, Internal exposure of the general population to DEHP and other phthalates - determination of secondary and primary phthalate monoester metabolites in urine, Environ. Res 93 (2003) 177-185

[8] U. Heudorf, V. Mersch-Sundermannb, J. Angerer, Phthalates: Toxicology and exposure, International Journal of Hygiene and Environmental Health, 210(5) (2007) 623-634.

[9] K. Holadova, G. Prokupkova, J. Hajslova, J. Poustka, Headspace SPME of phthalic acid esters from vegetable oil employing solvent based matrix modification, Analytica Chimica Acta, 528 (2007) 24-33

[10] X. Li, M. Zhong, S. Xu, C. Sun, Determination of phthalates in water samples using polyaniline-based solid-phase microextraction coupled with gas chromatography, Journal of Chromatography A, 1135 (2006) 101-108

[11] B. Cavaliere, B. Macchione, G. Sindona, A. Tagarelli, Tandem mass spectrometry in food safety assessment : the determination of phthalates in olive oil, Journal of Chromatography A, 1205 (2008) 137-143

[12] D. Sicar, S.J. Albazi, Y. Atallah, W. Pizzi, Validation and Application of an HPLC Method for Determination of Di (2-ethylhexyl) Phthalate and Mono (2-ethylhexyl) Phthalate in Liver Samples, Journal of Chromatographic Science, 46(7) (2008) 627-631

[13] C. Perez, M.C. Baricela Alonso, E. Pena Vasquez, P. Herbello Hermelo, P. Barmejo Barera, Phthalates determination in physiological saline solutions by HPLCES-MS, Talanta 75 (2008) 1184-1189

[14] P. Kebarle, L. Tang, From ions in solution to ions in the gas phase - The mechanism of electrospray mass spectrometry, Analytical Chemistry 65 (1993) 972A-986A

[15] D. Anđelković, Interakcija i specijacija hroma u model 
sistemima zemljišta i O-, N- i S-donor liganada prirodnog i antropogenog porekla, PhD thesis, University of Niš, 2012.

[16] S. Banerjee, S. Mazumdar, Electrospray Ionization Mass Spectrometry: A Technique to Access the Information beyond the Molecular Weight of the Analyte, 2012 (2012) $1-40$

[17] D. H. Anđelković, R. S. Nikolić, D. Z. Marković, T. D. Anđelković, G. M. Kocić, Z. B. Todorović, A. Lj, Bojić, A study of chromium interaction with O-donor humic-like ligands using electrospray-ionization mass spectrometry, Journal of Serbian Chemical Society 78 (2012) 137-154

\section{Izvod \\ PROCENA LINARNOSTI ODZIVA PRI ODREĐIVANJU FTALATA ESI-MS METODOM PUTEM INJEKTIRANJA UZORKA LOOP TEHNIKOM}

Tatjana D. Anđelković ${ }^{1}$, Gordana M. Kocić , Darko H. Anđelković1, Ivana S. Kostić1, Danica S. Milojković ${ }^{1}$

1 Univerzitet u Nišu, Prirodno-matematički fakultet, Niš, Srbija

2 Univerzitet u Nišu, Medicinski fakultet, Niš, Srbija UDK 535.243

Testirana je ESI-MS tehnika za kvantitativno određivanje šest najčešće korišćenih ftalata (DMP, DnBP, BzBP, DEHP, DiNP, DiDP). Postupak je sproveden snimanjem hromatograma dobijenog nakon injektiranja uzorka rastvora ftalata različite koncentracije korišćenjem Loop tehnike. Testiranje je vršeno utvrđivanjem linearnosti između koncentracije ftalata i površine njihovih pikova u hromatogramu za maseni opseg koji odgovara protonovanom molekulskom jonu, kao i jonu adukta sa natrijumom. Analiza je pokazala da postoji zadovoljavajuća linearnost između koncentracije ftalata i površine pika u hromatogramu praćenjem molekulskog jona i jona adukta sa natrijumom za slučaj DiNP $(r>0,999)$ i DMP $(r>0,999$ za molekulski jon; $r>0,989$ za jon adukt sa natrijumom). Kod analize DiDP kao pouzdaniji jon za praćenje pokazao se molekulski jon, dok se kod BzBP kao pouzdaniji pokazao jon adukt sa natrijumom. DEHP daje približno isti koeficijent korelacije za oba monitoring jona, molekulski jon i jon adukt sa natrijumom ( $r=0,98371$ i 0,98962, respektivno). Koeficijenti korelacije dobijeni za molekuIski monitoring jon DnBP i jon adukta sa natrijumom, pokazali su nižu vrednost od ostalih koeficijenata linearnosti ( $r=0,96034$ i 0,94669, respektivno).
Ključne reči: ftalati, ESI-MS, Loop tehnika injektiranja 